\title{
Uzaktan Algılama Sistemleri için Elma ve Armut Yapraklarının Dielektrik Parametrelerinin Ölçülmesi ve Modellenmesi
}

\author{
Abdullah GENÇ* \\ Isparta Uygulamall Bilimler Üniversitesi, Mekatronik Mühendisliği Bölümü, Isparta \\ (ORCID: 0000-0002-7699-2822)
}

\begin{abstract}
Öz
Gelişen teknolojilerin bitkilerde gerek uzaktan izleme/kontrol gerekse uzaktan algılama (UA) sistemlerinde yaygın bir şekilde kullanılması, bitki kümesinin verim ve kalitenin artmasında önemli rol oynamaktadır. Bitkilerde dielektrik özelliklerin belirlenmesi, bu alanda geliştirilecek sistemler için önem arz etmektedir. Bundan dolayı, bazı bitki türlerinin sıklıkla bulunduğu bölgelerde, elektromanyetik (EM) dalgaların bitki yüzeylerine nüfuz etme açısından dielektrik parametrelerinin çalışılmasını gerektirmektedir. Bu çalışmada Isparta bölgesinde çok yoğun olarak üretilmekte olan elma (Malus communis) ve armut (Pyrus communis) ağaçlarının yapraklarına ait dielektrik parametreler Dalga Kılavuzu İletim Hattı yöntemiyle ölçülmüştür. Ölçümler 3,3-4,9 GHz arasında (WR229 dalga kılavuzu) yapılmış ve nem oranı ve frekansa bağlı elma ve armut yapraklarının dielektrik karakteristikleri incelenmiştir. Elma yapraklarının dielektrik ölçüm verileri kullanarak frekans ve nem oranına (NO) bağlı, eğri uydurma yöntemiyle yeni bir model önerilmiştir. Bu model, elma türüyle aynı aileden olan armut yaprağının dielektrik ölçüm sonuçlarıyla karşılaştırılarak önerilen modelin doğruluğu test edilmiştir. Modelin performansını göstermek için determinasyon katsayısı $R^{2}$ ve hataların ortalama karekökü (RMSE) değerleri sırasıyla 0,995 ve 0,625 olarak elde edilmiştir.
\end{abstract}

Anahtar kelimeler: Dielektrik ölçümü, uzaktan algılama, nem oranı, elma yaprağı, armut yaprağı.

\section{Measurement and Modeling of Dielectric Parameters of Apple and Pear Leaves for Remote Sensing Systems}

\begin{abstract}
The widespread use of developing technologies in both remote monitoring/control and remote sensing (RS) systems in vegetative materials plays an important role in increasing the efficiency and quality of the plants. Determination of dielectric properties in plants is important for the systems to be progressed in this field. Therefore, it is necessary to study dielectric parameters in order to penetrate plant surfaces of electromagnetic (EM) waves in areas where some plant species are frequently found. In this study, dielectric characteristics of the leaves of apple and pear trees which are produced in Isparta region are measured with Waveguide Transmission Line method. Measurements are made between 3.3-4.9 GHz (WR229 waveguide) and dielectric characteristics of apple and pear leaves depending on moisture content (MC) and frequency are investigated. A new model is proposed via a curve fitting method based on the frequency and moisture content using dielectric measurement data of apple leaves. The accuracy of the proposed model is tested by comparing the model results with the dielectric measurement results of the pear which belong to the same family with the apple species. To make sure the performance of the model well enough, the coefficient of determination $R^{2}$ and root mean square error (RMSE) values are obtained as 0.995 and 0.625 , respectively.
\end{abstract}

Keywords: Dielectric measurement, remote sensing, moisture content, apple leaf, pear leaf.

\section{Giriş}

Malzemelerin temel bir özelliği olan kompleks dielektrik sabiti, malzemenin elektromanyetik (EM) dalgalarla etkileşimini ve davranışını belirler. Malzemenin dielektrik özellikleri, uygulanan EM

\footnotetext{
"Sorumlu yazar: abdullahgenc@isparta.edu.tr

Geliş Tarihi: 03.08.2019, Kabul Tarihi: 20.03.2020
} 
dalgalarının malzeme içerisindeki depo edilme ve ısıya dönüşme oranlarını doğrudan etkiler. Mikrodalga teknolojisinin gelişmesiyle birlikte Mikrodalga Uzaktan Algılama (MDUA) ve mikrodalga 1sıtma/kurutma uygulamaları yaygınlaşmıştır. Ancak, bu teknolojilerin etkin kullanımı için malzemenin dielektrik özelliklerinin öncelikle belirlenmesi gereklidir. Bununla birlikte, radyo frekans dalgalarının yayılım ortamının belirlenmesinde dielektrik özelliklerinin bilinmesi önemlidir.

Kayılı ortamlarda kompleks dielektrik sabitinin reel kısmı $\left(\varepsilon^{\prime}\right)$, EM enerjinin malzeme içerisinde ne kadar depo edildiğini belirlerken, sanal kısmı ise EM yayılım hızını, zayıflamayı ve iletim parametrelerini belirler. Genel olarak, homojen, yön bağımsız ve kayıplı bir ortam için kompleks dielektrik sabiti Denklem 1'de verilmiştir [1].

$\varepsilon^{*}=\varepsilon_{0}\left[\varepsilon_{\mathrm{r}}-\mathrm{j} \frac{\sigma}{\omega \varepsilon_{0}}\right]$

Burada $\varepsilon_{0}$ boşluğun dielektrik sabiti olup, $\sigma$ iletkenlik, $\omega$ açısal frekans ve $\varepsilon_{r}$ bağıl dielektrik geçirgenlik sabitidir.

$\varepsilon^{\prime}=\varepsilon_{0} \varepsilon_{r}$

$\varepsilon^{\prime \prime}=\frac{\sigma}{\omega}$

Burada, malzemenin kayıp tanjantı $\varepsilon^{\prime \prime} / \varepsilon^{\prime}$ olduğu için Denklem 4'deki gibi ifade edilir. Malzeme içerisindeki güç kaybının, frekansa ve malzemenin dielektrik sabitine bağlı olduğu bu denklemde görülmektedir.

$\tan \delta=\frac{\sigma}{\omega \varepsilon_{\mathrm{r}} \varepsilon_{0}}$

Bitkilerde dielektrik parametre ölçümleri 1910'lu yıllara dayanmasına rağmen [2], günümüzde 1sitma, kurutma ve uzaktan algılama (UA) gibi mikrodalga uygulamalarında bitkisel malzemelerin (yaprak, dal, meyve, vb.) kullanımı artmıştır. Mikrodalga 1sıtma/kurutma yöntemlerinde, uzaktan algılama/izleme ve soğurucu malzeme çalışmalarında tarımsal ürünlerin dielektrik ölçümleri yaygın bir şekilde kullanılmaktadır. Bu durum, bitkilerde dielektrik parametrelerinin ölçümü ve belirlenmesinde temel motivasyon kaynağı oluşturmaktadır. Bazı bitkilerin dielektrik ölçümlerinin sayısal verileri ilk olarak Nelson tarafindan [3] elde edilmiştir. Bitki kümesine gelen EM dalgaları, bitkilerin yaprak, gövde, dal ve meyve yüzeylerine nüfuz eder ve yüzeyde yansıma, kırılma, soğurulma ve saçılma gibi EM davranışları gerçekleşir. Bu EM davranışlarında baskın etken, yapraklardır [4]. Dolayısıyla yaprakların bu davranışlardaki etkisinin belirlenmesi önemlidir [5]. UA uygulamaları mikrodalga dâhil çeşitli yöntemlerle yapılabilir. Ancak, mikrodalga tekniklerinin diğer yöntemlere göre bazı avantajları bulunmaktadır. Bunlar; mikrodalgaların bitki örtüsü ve toprağa nüfuz etmesi, toprak ve bitkilerdeki su içeriğine duyarlı olmaları ile bulutlu havalarda ve gecelerde yayılabilmeleridir.

Bitki yaprak ve gövdelerinin UA üzerindeki etkileri ve EM saçılma modelleriyle ilgili çeşitli çalışmalar bulunmaktadır [5-7]. UA uygulamaları, bitki örtüsünün izlenmesi ve çeşitli askeri amaçlarda yaygın olarak kullanılmaktadır. Ayrıca, bitki örtüsündeki dielektrik parametreleri, büyük ölçüde bitkinin nem oranına (NO) bağlı olduğundan bitkilerin ve toprağın suya olan ihtiyaçları tespit edilerek sulama işlemlerinin verimli hale getirilmesi gerçekleşebilir. Böylece, mikrodalga uygulamaları ile bitkilerin sulama işlemi profesyonel olarak yapılır [8].

Daha önce bahsedilen uygulamalardan farklı olarak, bitkilerin dielektrik parametreleri, malzemelerin soğurma özelliklerini belirlemede kullanılır. Günümüzde çoğu soğurucu malzeme, polimer tabanlıdır ve zamanla soğurma özellikleri azalmaktadır. Polimer tabanlı bu malzemeler, aynı zamanda çevre ve sağlık açısından da bazı riskler içerir. Bu risklerin etkisini ortadan kaldırmak için çeşitli bitkiler soğurucu malzeme olarak kullanılabilir. Muz gibi soğurucu özelliğe sahip lifli bitkilerin dielektrik karakteristikleri literatürde elde edilmiştir [9-11]. Bu çalışmalara göre, muz yapraklarının \%43,5 oranında karbon içerdiği için soğurucu malzeme olarak kullanılabilir.

Mikrodalga 1sıtma/kurutma işlemlerinde, bitkilere gelen EM enerji belli bir oranda soğurularak 1sıya dönüşür. Malzemede hacim başına yayılan güç miktarı Denklem 5'de verilmiş̧ir [12]. 
$P=E^{2} \cdot \sigma=55,63 \cdot 10^{-12} \cdot f \cdot E^{2} \cdot \varepsilon^{\prime \prime}$

Burada $P$ malzemede emilen güç, $E$ ise elektriksel alandır. Buna göre malzemede emilen güç, malzemenin dielektrik sabitine doğrudan bağlıdır. Literatürde mikrodalga 1sıtma/kurutma işlemleriyle ilgili çalışmalar yapılmıştır $[13,14]$. Bu işlemler sayesinde geleneksel yöntemlere göre hem enerji hem de zaman tasarrufu elde edilmiştir. Bitkilerin dielektrik özelliklerinin belirlenmesinde birçok teknik kullanılmaktadır. $100 \mathrm{MHz}$ altı frekans bölgesinde paralel plaka ve toplu elemanlar yöntemi, daha üst frekans bölgesinde ise iletim hatt1, koaksiyel prob, boşluk rezanatörü, dalga kılavuzu ve serbest uzay ölçüm teknikleri kullanılmıştır [15-17]. Bu çalışmalarda genel olarak bitkilerin içerdiği su miktarına bağlı olarak belli frekanslardaki dielektrik parametreler ölçülmüştür. Bitki yaprakları, hem gövdeden koparılmadan önce [18] hem de koparıldıktan sonra dielektrik ölçümleri yapılabilir. Bitkinin koparılıp belli oranlarda nem miktarından arındırılarak yapılan ölçümlerin yanında, tamamen toz haline getirilip yapılan ölçümlerde mevcuttur. Başta tahıl ürünleri olmak üzere mısır bitkisi üzerinde bazı çalışmalar yapılmıştır $[19,20]$. Bu sayede, meyvelerin olgunlaşma durumu ve kalitesi belirlenebilir.

Türkiye, 2 milyon tonu aşan yıllık elma üretimiyle Çin ve ABD'den sonra dünyada üçüncü sırada yer almaktadır. Isparta bölgesi ise yaklaşı yıllık altı yüz bin ton elma üretim kapasitesi ile Türkiye'nin \%25'lik üretimini karşıllamaktadır. Ayrıca Türkiye armut üretiminde de yıllık 500 bin tonluk üretim kapasitesiyle dünyada ihracat yapan ülkeler arasındadır ve Isparta bölgesinde farklı alanlarda, özellikle Yalvaç bölgesinde yoğun armut üretimi yapılmaktadır. Hem UA ve ürün izleme otomasyonu hem de diğer mikrodalga uygulamaları için dielektrik parametrelerinin belirlenmesiyle ilgili çalışmalara ihtiyaç vardır ve bu çalışmadaki temel motivasyonumuzdur.

Bu çalışmada, sabit sıcaklıkta NO ve frekansa bağlı olmak üzere birbiriyle aynı aileden olan elma (Malus communis) ve armut (Pyrus communis) yapraklarının dielektrik karakteristikleri ölçüm sonuçlarıyla elde edilmiştir. Elma yapraklarının dielektrik ölçüm verileri kullanarak eğri uydurma yöntemiyle yeni bir model önerilmiştir. Elma türüne akraba olan armut yaprağıyla ilgili dielektrik ölçümleriyle modelin doğruluğu test edilmiştir. Ölçümlerde Dalga Kılavuzu İletim Hattı tekniği kullanılmıştır. Ölçümler WR229 dalga kılavuzuyla 3,30-4,90 GHz frekans bandında yapılmıştır. Bu çalışmada frekans bandının 3,3-4,9 GHz olarak seçilmesinin temel nedeni, mısır ve pirinç vb. gibi bazı bitkilerin boylarını izlemek ve nem oranına bağlı bitkinin dielektrik sabitini kullanarak bitkinin su ihtiyacını tespit etmek amacıyla literatürde S-bandının yaygın olarak kullanılmasıdır. Örneğin sentetik açıklıklı radar (SAR) tekniğininde genellikle S-bandında kullanılır. Çalışmanın 2. Bölümü’nde kullanılan dielektrik ölçüm yöntemi verilmiştir. 3. Bölüm, elde edilen ölçüm sonuçları ve önerilen modelden oluşur ve 4. Bölüm'de sonuçlar değerlendirilmiştir.

\section{Materyal ve Metot}

\subsection{Dielektrik Ölçüm Yöntemi}

$\mathrm{Bu}$ çalışmada dielektrik parametrelerin belirlenmesi amacıyla Dalga Kılavuzu İletim Hattı yöntemi kullanılmıştır. Bu yöntemde, frekans bandına göre ilgili dalga kılavuzu seçilmelidir. Çalışmadaki tüm ölçümler, Akdeniz Üniversitesi'nde bulunan Endüstriyel ve Medikal Uygulamalar Mikrodalga Uygulama ve Araştırma Merkezi (EMUMAM) Laboratuvarında gerçekleştirilmiştir. Ölçümlerde vektör network analizör, iki adet RF koaksiyel kablo, iki adet dalga kılavuzu-koaksiyel adaptör ve bir adet flanş kullanılmıştır. Vektör network analizör (VNA) olarak Anritsu MS4624B modeli (10 MHz - $9 \mathrm{GHz})$ kullanılmıştır. Ölçümler için dalga kılavuzu, Vektör Network Analizör'e (VNA) RF koaksiyel kabloyla bağlanır. Alıcı ve verici durumunda olan iki dalga kılavuzu ve buna uyumlu bir adet flanş kullanılır. Ölçülecek numune, flanş arasına konularak ölçüme hazır hale getirilir. Ölçümler 3.30-4.90 GHz aralığında yapılmıştır. Bunun için frekans bandıyla uyumlu WR229 dalga kılavuzu seçilmiştir.

Ölçümlerde kullanılan numunelerin (yapraklar) kurutma aşamasında oluşan kıvrılmaları ve kırılmaları engellemek, dielektrik ölçümün doğruluğu için önemlidir. Bundan dolayı bu olumsuz etkiyi ortadan kaldırmak için yaprakların her iki tarafında, flanş ebatlarına uygun şeffaf plastik camlar (plexiglass) kullanılmıştır. Kullanılan şeffaf plastik camların dielektrik ölçümünde az da olsa etkisinin olduğu gözlenmiştir ve bu çalışmada plastik camın ölçüm üzerinde etkisi dikkate alınmıştır. Yaprakların homojen olarak kurutulmasını sağlamak amacıyla Bilgisayarlı Sayısal Kontrol (CNC) yöntemiyle plastik cam üzerinde eşit mesafede $8 \times 4$ sayıda bir mm'lik delikler açılmıştır. Numuneler, ölçümden 
önce 48 saat boyunca saf suda bekletilerek suya doymuş hale getirilmiştir. Numunelerin suda bekletildiği bu süre içerisinde ağılıkları her 12 saatte bir ölçülmüştür. 48. saat sonundaki ağırlık ölçümlerinde değişimin $\pm \% 0,3$ olduğu saptanmıştır. Ölçümler suda bekletilen 48 saatlik sürenin hesaba katılmadığı durumda yaprak başına yaklaşı üçer gün sürmüştür.

Ölçüme başlamadan önce suya doymuş yapraklar WR229 dalga kılavuzu boyutları için neşterle kesilmiştir. Numunelerin $S_{11}$ ve $S_{21}$ değerleri ölçülmüştür ve her ölçüm sonrasında mgr hassasiyetine sahip hassas teraziyle ağırlıkları ölçülmüsstür. Suya doymuş yapraklar mikrodalga firında adım adım kurutulmuştur. Kurutma ve ölçüm adımları, yapraklar tamamen kuruyana kadar devam etmiştir. Son kurutma aşamasından sonra, firın içerisindeki sıcaklık $70^{\circ}$ iken numuneler bu ortamda 24 saat bekletilmiştir. Daha sonra tamamen kuruyan numunelerin ağırlık ve S-parametreleri alınarak ölçüm süreci tamamlanmıştır. Numunelerin ölçüm yapıldığı odanın sıcaklığının da $27^{\circ}$ 'dir.

Şekil 1'de ölçüm ortamı görülmektedir. Şekil 1a'da dalga kılavuzlarıyla beraber ölçüme hazır olan sistem verilmiştir. Şekil $1 b$ ve Şekil 1c, sırasıyla içi boş ve içi plastik camla dolu flanşlar göstermektedir. Şekil 1d armut yaprağını, Şekil 1e ise elma yaprağını göstermektedir.

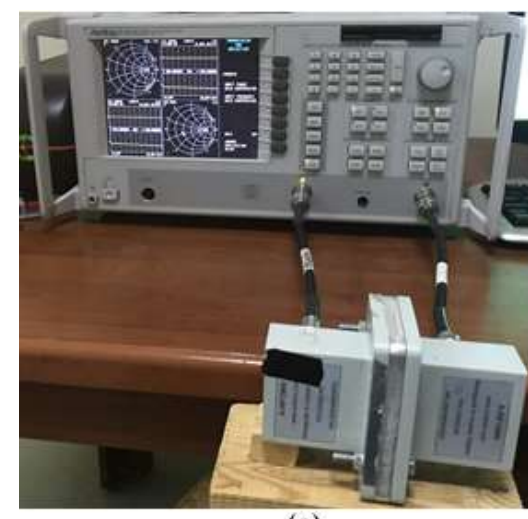

(a)

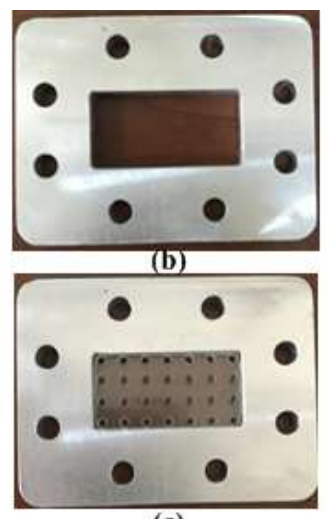

(c)

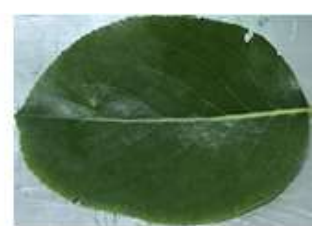

(d)

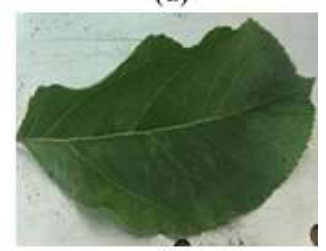

(e)

Şekil 1. Ölçüm ortamı

Daha önce belirtildiği gibi yaprakların kurutulma süreci adım adım gerçekleşmiştir. Tablo 1'de elma ve armut yapraklarının WR229 için yapılan kurutma aşamalarında hesaplanan NO değerleri verilmiştir. Kurutma işlemine geçmeden önce suya doymuş elma yaprağının ağırlığının 405 mg olduğu belirlenmiştir. Kurutmanın her adımında elma yaprağının ağırlığı düşerek 144 mg'da sabit kalmıştır. Bu ağırlık, yaprağın firında $70^{\circ}$ 'de 24 saat bekletilerek ve tamamen kurutulmuş olan ağırlığıdır. Bu ağırlık düşüşüne bağlı olarak NO da düşmüştür. Suya doymuş armut yaprağının ağırlığ $370 \mathrm{mg}$ iken, tamamen kuru numune ağırlığ 185 mg'dır. NO değerleri \%100'den başlayarak adım adım azalarak \%0'a kadar düşmüştür. Suya doymuş elma ve armut yapraklarının kurutulmadan önceki nem miktarı \%100 iken, tamamen kuru yapraklardaki NO ise \%0 olarak Eşitlik 6'ya göre hesaplanmıştır [21].

Tablo 1. WR229 (3,30-4,90 GHz) için elma ve armut yaprakların NO değişimi

\begin{tabular}{cccc|cccc}
\hline \multicolumn{4}{c}{ Elma yaprağı } & \multicolumn{4}{c}{ Armut yaprağı } \\
\hline $\begin{array}{c}\text { Toplam } \\
\begin{array}{c}\text { ağırlık } \\
(\mathrm{mg})\end{array}\end{array}$ & $\begin{array}{c}\text { Kurumuş } \\
\text { ağırlık } \\
(\mathrm{mg})\end{array}$ & $\begin{array}{c}\text { Nem } \\
\text { miktarı } \\
(\mathrm{mg})\end{array}$ & $\begin{array}{c}\text { Nem } \\
\text { oranı } \\
(\%)\end{array}$ & $\begin{array}{c}\text { Toplam } \\
\text { ă̆ırlık } \\
(\mathrm{mg})\end{array}$ & $\begin{array}{c}\text { Kurumuş } \\
\text { ağırlık } \\
(\mathrm{mg})\end{array}$ & $\begin{array}{c}\text { Nem } \\
\text { miktarı } \\
(\mathrm{mg})\end{array}$ & $\begin{array}{c}\text { Nem } \\
\text { oranı } \\
(\%)\end{array}$ \\
\hline 405 & 144 & 261 & 100 & 370 & 185 & 185 & 100 \\
260 & 144 & 116 & 44.44 & 316 & 185 & 131 & 70.81 \\
200 & 144 & 56 & 21.46 & 255 & 185 & 70 & 37.84 \\
175 & 144 & 31 & 11.88 & 208 & 185 & 23 & 12.43 \\
153 & 144 & 9 & 3.45 & 203 & 185 & 18 & 9.73 \\
144 & 144 & 0 & 0 & 185 & 185 & 0 & 0 \\
\hline
\end{tabular}

Su miktarl $=m_{\text {doymuş }}-m_{k u r u}$

$N O=\frac{m_{\text {ölçülen }}-m_{k u r u}}{\text { Su miktarl }}$ 
Burada $m_{\text {öls̆ülen }}$ her bir kurutma adımında numunenin ölçülen ağırlığı, $m_{\text {doymus }}$ numunenin suya doymuş ilk ağırlı̆̆ ve $m_{\text {kuru }}$ numunenin tamamen kurumuş son ağırlığıdır. Nem oranı $(N O)$, Eşitlik 7 yardımıyla elde edilir.

NO değerinin dielektrik sabiti üzerindeki etkisini görebilmek için ölçülen S-parametrelerinden bağıl dielektrik sabiti $\left(\varepsilon^{\prime}\right)$ ve dielektrik kaybın $\left(\varepsilon^{\prime \prime}\right)$ hesaplanması gerekir. Literatürde bu durumla ilgili farklı algoritmalar olsa da en çok bilinen ve kabul gören yöntem Nicolson-Ross-Weir (NRW) algoritmasıdır [22]. Bu çalışmada NRW algoritması kullanılarak yaprakların dielektrik parametreleri hesaplanmıştır. Bu yöntemle elde edilen dielektrik parametrelerinin doğru hesaplanması için iki durum göz önünde bulundurulmalıdır. Bunların ilki, yaprakların belli kalınlığa sahip olmasıdır. Diğeri ise ölçüm hatalarının hassasiyeti frekans yükseldikçe arttı̆̆ından dolayı hataları en aza indirmek için ölçüm ve test hazırlığının dikkatli yapılmasıdır. Denklemler 8-14 kullanılarak NRW algoritmasıyla dielektrik geçirgenlik sabiti hesaplanır. $S_{11}$ değeri, giriş portundan gönderilen EM dalganın gücünün, aynı porta gelen EM dalgasının gücüne oranı iken, $S_{2 l}$ değeri ise, giriş portundan gönderilen EM dalganın gücünün, çıkış portuna iletilen EM dalgasının gücüne oranı olarak ifade edilebilir.

$S_{11}=\frac{\Gamma\left(1-T^{2}\right)}{\left(1-\Gamma^{2} T^{2}\right)}$

$S_{21}=\frac{T\left(1-I^{2}\right)}{\left(1-\Gamma^{2} T^{2}\right)}$

Burada, $\Gamma$ yansıma katsayısı iken, $T$ iletim katsayısıdır.

$$
\begin{aligned}
& X=\frac{S_{11}^{2}-S_{21}^{2}+1}{2 S_{11}} \\
& \Gamma=X \pm \sqrt{X^{2}-1} \\
& T=\frac{S_{11}+S_{21}-\Gamma}{1-\left(S_{11}+S_{21}\right) \Gamma}
\end{aligned}
$$

$L$, numunenin kalınlığıdır. Manyetik olmayan malzemelerde $\mu_{r} \approx 1$ olarak alınır ve bu çalışmada ölçümü yapılan yapraklar manyetik malzeme olmadığı için NWR hesaplamalarında $\mu_{r} \approx 1$ alınmıştır [23].

$$
\begin{aligned}
& \frac{1}{\Lambda^{2}}=-\left[\frac{1}{2 \pi L} \ln \left(\frac{1}{T}\right)\right]^{2} \\
& \varepsilon_{r}=\frac{\lambda_{0}}{\mu_{r}}\left(\frac{1}{\lambda_{c}^{2}}-\left[\frac{1}{2 \pi L} \ln \left(\frac{1}{T}\right)\right]^{2}\right)
\end{aligned}
$$

\section{2. Ölçüm Düzeneğindeki Sistematik Hataların Giderilmesi}

Ölçüm düzeneğindeki sistematik hataların giderilmesi için yaygın olarak kullanılan yöntemler, Gömülü (Embedding) ve Doğrudan Yansıma Hattı (Thru Reflect Line) yöntemleridir. Gömülü yöntem, testte kullanılan modelin hatalarını yok etmek için matematiksel ifadelerden yararlanır. Bu yöntem, modellerde kalibrasyon tekniklerinin kullanılmadığı koaksiyel olmayan cihazlarda tercih edilir [24] ve S-parametrelerinden yararlanır. Bundan dolayı bu yöntem, modeldeki hataların testi yapılmadan uygulanamaz. Dielektrik ölçümlerinde kullanılan plastik camlar, Test Altındaki Cihazlar (Equipment Under Test) gibi davrandığı için ölçümlerde bu plastik camların S-parametrelerinin belirlenmesi gerekir. Dolayısıyla hem flanş hem de bu plastik camların dielektrik ölçüm üzerindeki etkileri giderilmelidir. Bu durumun literatürdeki yöntemlerle [25] uyumlu olmasına dikkat edilmelidir.

Gömülü yöntemlerin yanı sıra, dielektrik ölçümlerde oluşabilecek hataları en aza indirmek için farklı türde kalibrasyon yöntemleri vardır. Bunların arasında Doğrudan Yansıma Hattı Yöntemi, yaygın olarak kullanılan ve doğru sonuçlar veren bir yöntemdir [26]. Bu teknik, ölçüm yöntemlerindeki doğruluğu gösterebilen bir referans yöntem olarak da bilinir. Bu yüzden, bu yöntemin doğruluğunu 
doğrudan etkileyebilecek hataların kaynakları dikkate alınmalıdır. Düşük frekanslarda ihmal edilen hata oranları, yüksek frekanslarda ölçüm doğruluğunu daha fazla etkiler.

\section{3. Ölçüm ve Kalibrasyon Yöntemini Doğrulama Testi}

Teflon, dielektrik ölçüm doğruluğunda kolay ulaşılabilirliği ve düşük maliyetinden dolayı yaygın olarak kullanılan bir malzeme türüdür [27]. Bu malzemenin $\varepsilon^{\prime}$ ve $\varepsilon^{\prime \prime}$ değerleri frekans değişimiyle neredeyse sabit olup, sırasıyla 2 ve 0 'dır. Bu çalışmada kalınlığ $2,5 \mathrm{~mm}$ olan teflon tabaka kullanılarak dielektrik parametrelerinin ölçümü yapılmıştır. Şekil 2 incelendiğinde teflon malzemenin ölçülen $\varepsilon^{\prime}$ ve $\varepsilon^{\prime \prime}$ değerlerinin iyi sonuçlar verdiği görülmektedir. Bu sonuçlara göre, çalışmadaki test düzeneği ve kalibrasyon yönteminin doğruluğu tespit edilmiştir.

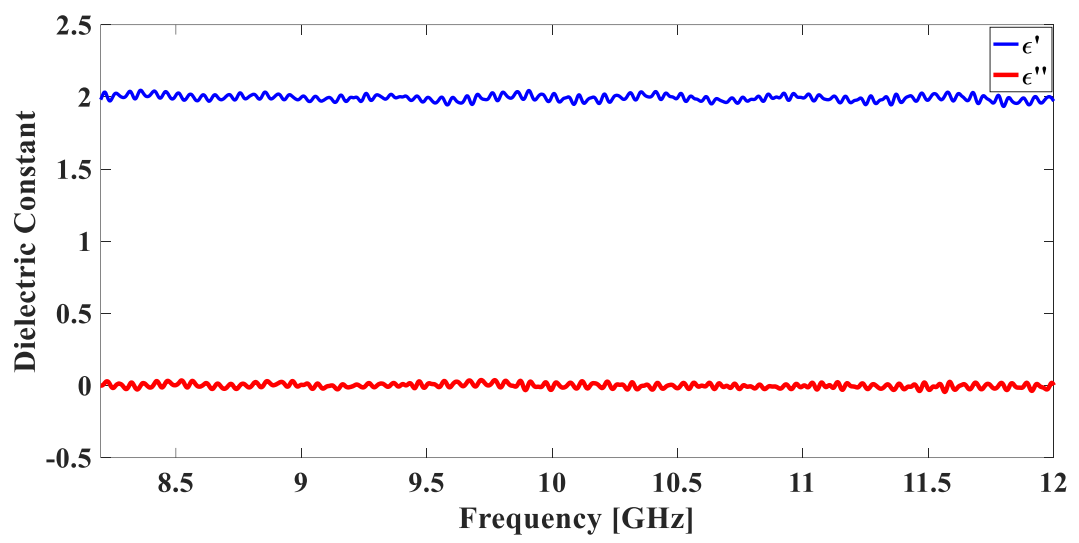

Şekil 2. 2,5 mm kalınlığındaki teflonun dielektrik parametreleri

\section{Bulgular}

\section{1. Ölçüm Sonuçları ve Önerilen Model}

Giriş bölümünde belirtildiği gibi ölçümlerde Elma ve Armut yaprakları numune olarak kullanılmıştır. Dalga k1lavuzu olarak 3,30-4,90 GHz frekans bandına uyumlu WR229 dalga k1lavuzu kullanılmıştır. Her bir numune için $\varepsilon^{\prime}$ ve $\varepsilon^{\prime \prime}$ değerleri $24^{\circ} \mathrm{C}$ oda sıcaklığında, frekans ve NO değerlerine bağlı olarak ölçülmüş̧ür. VNA'dan elde edilen $S_{11}$ ve $S_{2 l}$ değerleri kullanılarak 2. Bölüm'de bahsedilen NRW algoritması kullanılarak $\varepsilon^{\prime}$ ve $\varepsilon^{\prime \prime}$ değerleri hesaplanmıştır. Bu frekans bandı için ölçüm adım sayısı 2 MHz olup 801 farklı frekans noktasında ölçüm yapılmıştır.

Şekil 3'te elma yaprakları için ölçülen $\varepsilon^{\prime}$ değerleri verilmiştir. $\varepsilon$ ' değerinin, frekans azalışı ve NO artışı ile arttı̆̆ gözlenmiştir. Bu benzer değişimlerin $\varepsilon^{\prime \prime}$ değerleri için de geçerli olduğu Şekil 4 'te görülmektedir.

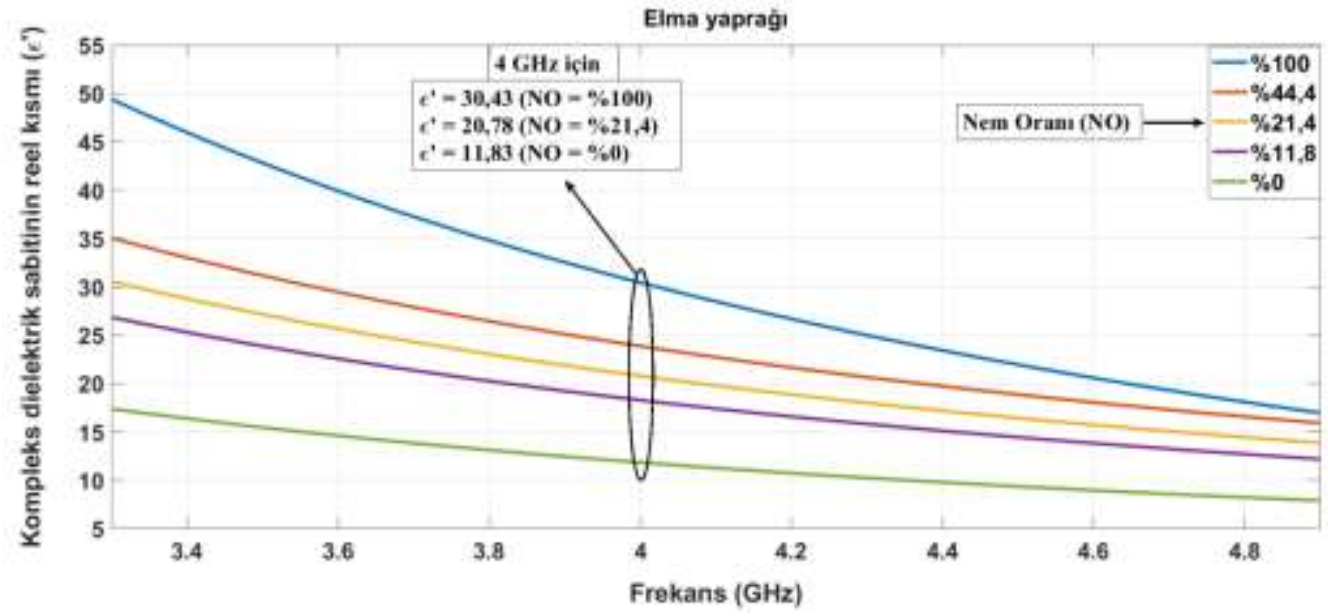

Şekil 3. Elma yaprakları için $\varepsilon^{\prime}$ değerinin frekans ve NO değerlerine göre değişimi 


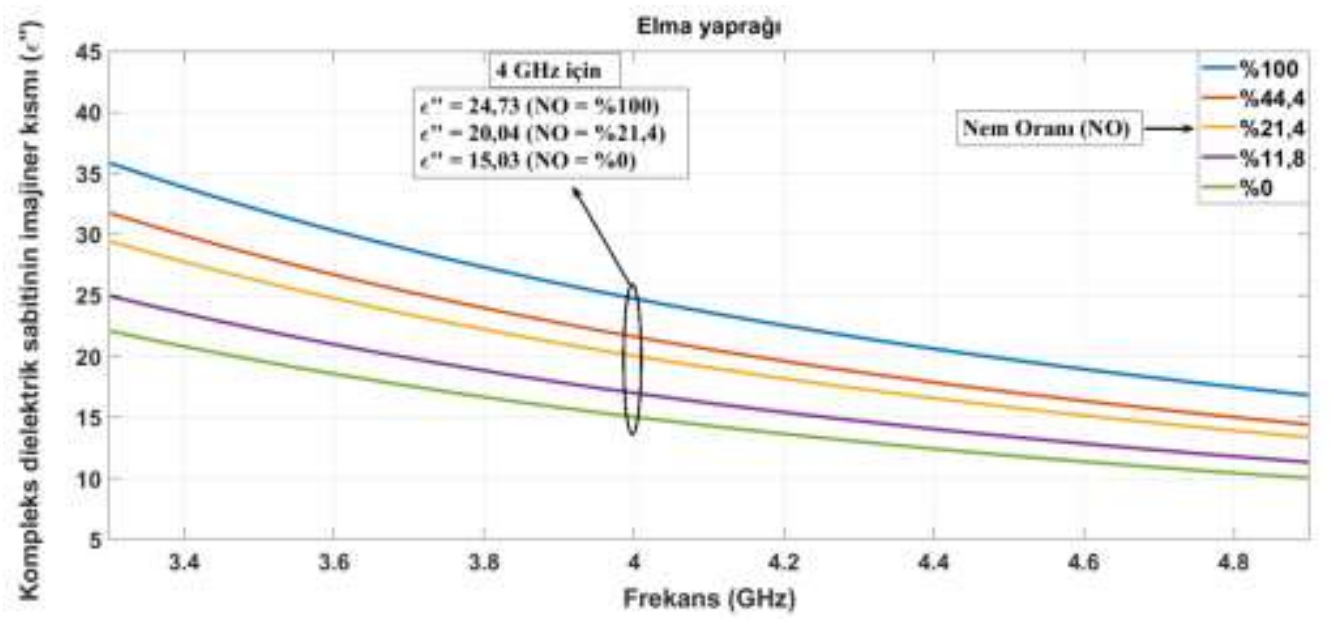

Şekil 4. Elma yaprakları için $\varepsilon^{\prime \prime}$ değerinin frekans ve NO değerlerine göre değişimi

Şekil 5 ve Şekil 6'da armut yaprakları için elde edilen $\varepsilon^{\prime}$ ve $\varepsilon^{\prime \prime}$ değerleri verilmiştir. Frekansa bağlı olarak $\varepsilon^{\prime}$ ve $\varepsilon^{\prime \prime}$ değerleri, eksponansiyel olarak azalmaktadır. NO'ya bağlı olarak ise bu değerler dikey eksende azaldığı görülmüsşür. Literatürde, saf suyun $\varepsilon^{\prime}$ değerleri, 3,3-4,9 GHz bandı için 78-74 aralığında değişmektedir [1]. Bu çalışmada elde edilen sonuçlar için suya doymuş yaprağın $\varepsilon^{\prime}$ ve $\varepsilon^{\prime \prime}$ değerleri, kuru yaprağınkine göre daha yüksektir ve bu durum NO'dan dolayı beklenen durumdur.

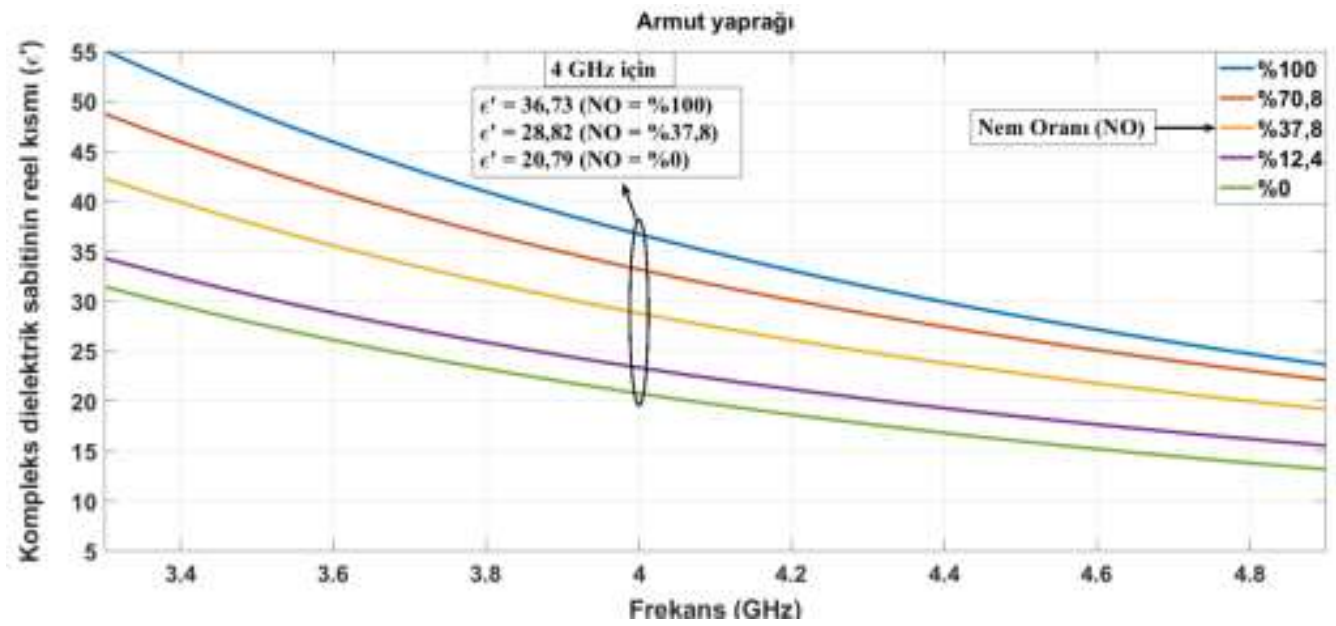

Şekil 5. Armut yaprakları için $\varepsilon^{\prime}$ değerinin frekans ve NO değerlerine göre değişimi

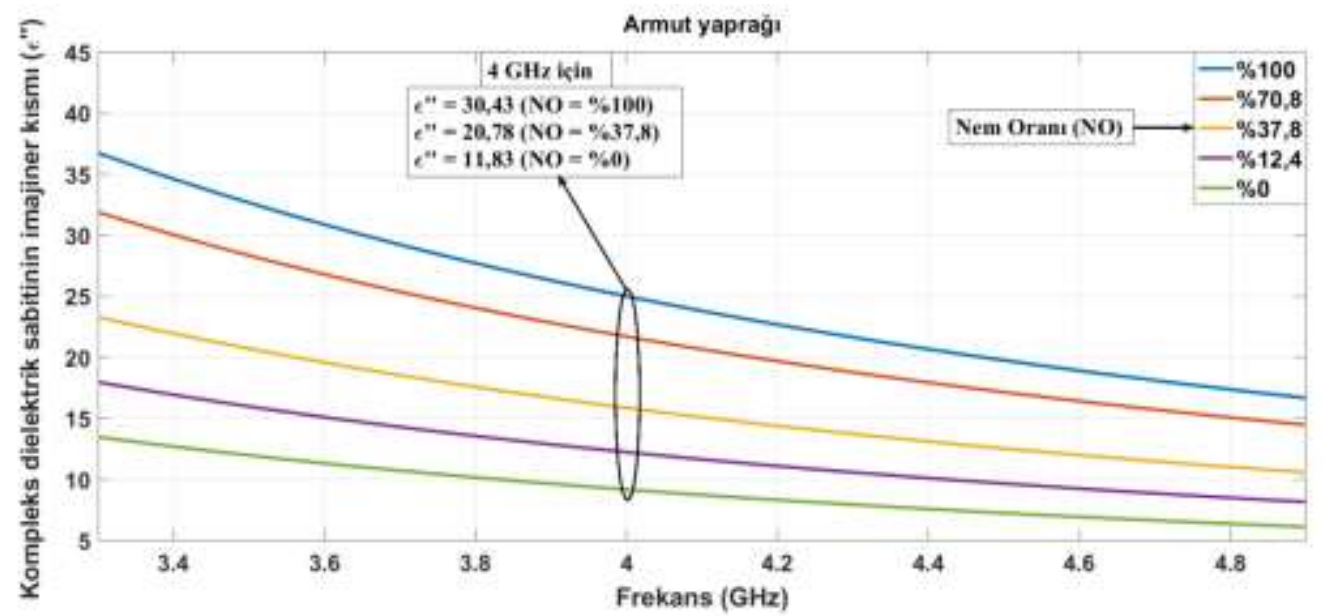

Şekil 6. Armut yaprakları için $\varepsilon^{\prime \prime}$ değerinin frekans ve NO değerlerine göre değişimi 
Elma yapraklarının ölçüm sonuçlarından elde edilen veriler kullanarak eğri uydurma yöntemiyle yeni bir model elde edilmiştir. Bu modelle, sabit sıcaklıkta $\left(24^{\circ} \mathrm{C}\right)$ frekans ve NO'ya bağlı dielektrik sabitini hesaplamak hedeflenmiştir. Denklem 15 'te verilen bu model, iki değişkenli ikinci dereceden bir kuvvet fonksiyonundan oluşur.

$\varepsilon_{r}(f, m)=a+b \cdot f^{-c}+d \cdot m^{e}+g \cdot f^{-c} \cdot m^{e}$

$\varepsilon_{r}=\sqrt{\varepsilon^{\prime 2}+\varepsilon^{\prime \prime 2}}$

Burada, $\varepsilon_{r}$ dielektrik sabiti, $f \mathrm{GHz}$ cinsinden frekans, $m$, 0-100 arasında değişen NO'dur. Denklem 16'da verilen $\varepsilon_{r}$ değeri, malzemenin dielektrik sabitinin hem reel hem de sanal kısmını içerdiği için modelde tercih edilmiştir. Elma yaprağ için WR229 dalga k1lavuzu için elde edilmiş modelin katsayıları $a=1,96$, $b=284,5, c=2,024, d=-0,5295, e=0,5372, g=36,93$ şeklindedir. Bu modeli oluşturmak için, Tablo 1'de elma yaprağının kurutma adımlarında hesaplanan 6 farkı NO değeri, veri olarak kullanılmıştır. Elde edilen modelin doğruluğunu test etmek için daha önce ölçümlerde kullanılan elma yapraklarından farklı ve \%33 NO’ya sahip başka bir elma yaprağ test numunesi olarak seçilmiştir. Önerilen modelde de aynı NO değerine sahip olması için Denklem 15'te verilen $m$ değeri 33 olarak girilmiştir. Şekil 7'de önerilen modelle test için seçilen elma yaprağının ölçülen değerleri karşılaştırılmıştır. Sonuçların birbiriyle çok uyumlu olduğu görülmektedir. Modelin performansını görmek için determinasyon katsayıs1 $R^{2}$ ve Hataların Ortalama Kare Kökü (RMSE) değerleri, tüm frekans ve NO değerlerine temel alınarak MATLAB ${ }^{\circledR}$ programıyla hesaplanmıştır. Buna göre modelin $R^{2}$ ve RMSE değerleri, sırasıyla 0,995 ve 0,625 olarak elde edilmiştir.

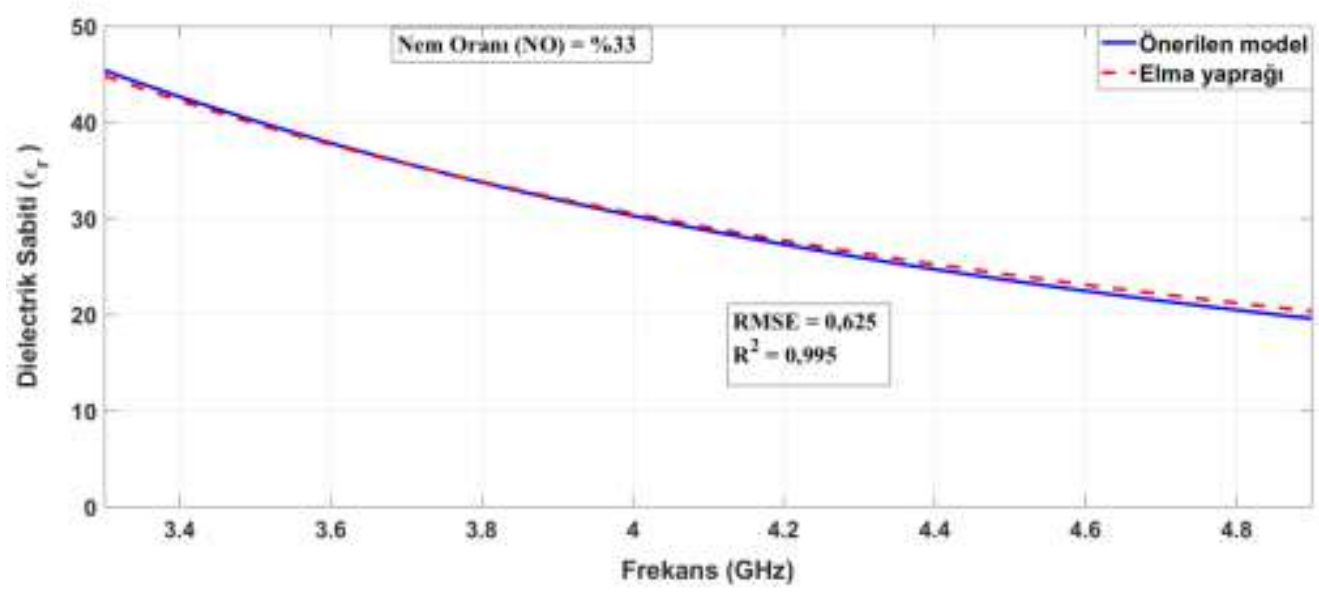

Şekil 7. Elma yaprağı ölçüm sonuçlarıyla önerilen modelin doğruluğunun test edilmesi

Elma yaprağına ait ölçüm verilerini kullanarak oluşturulan modelin armut yaprağı için kullanılabilirliği test edilmiştir. Burada, NO değeri \%40 olan bir armut yaprağ 1 ile aynı NO değerine sahip $(m=40)$ önerilen modelin sonuçları karşılaştırılmıştır. Bu sonuçların birbiriyle çok uyumlu olduğu Şekil 8'de görülmüş̧ür. Bu karşılaştırma, aynı akraba ve aynı aile içinde olan bir bitkinin yapraklarından elde edilen bir modelin aynı ailedeki diğer bitki türleri için uyumlu olabileceği hususunda fikir vermektedir. Elma ve armudun cins ve alt aileleri farklı olmasına rağmen her ikisi de gülgiller (Rosaceae) ailesi ve iki çenekliler (Magnoliopsida) sınıfında yer alırlar. Bundan dolayı elma yaprağı ölçüm verileriyle elde edilen model, armut yaprağı ölçüm sonuçlarıyla karşılaştırılmıştır. 


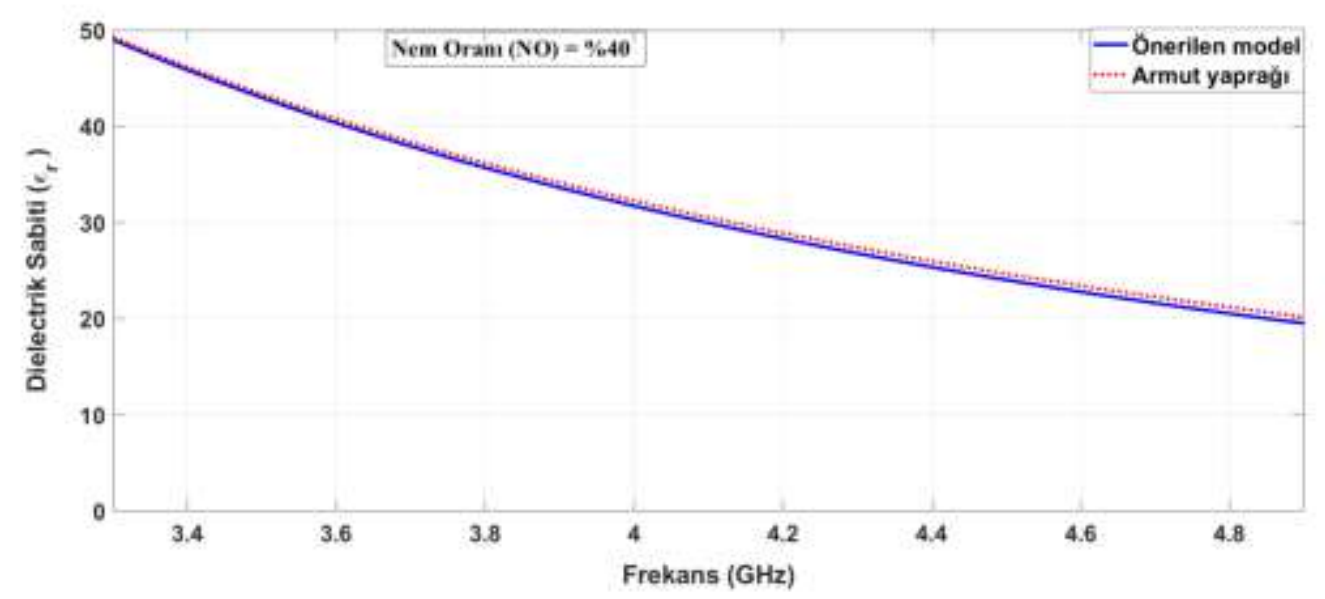

Şekil 8. Elma yaprağı modelinin armut yaprağı ölçüm sonuçlarıyla karşılaştırılması

Tablo 2'de bu çalışmada elde edilen sonuçlarla, yakın özellikteki diğer bitki yapraklarına ait ölçümlerin karşılaştırılması verilmiş ve elma yaprağının dielektrik parametrelerinin değişimi literatürdeki diğer yaprakların dielektrik parametrelerinin değişimiyle benzer olduğu görülmektedir. Bunun ise, yapraklardaki nem oranı ve frekansın dielektrik parametrelerdeki belirleyiciliğinden kaynaklandığı düşünülmektedir.

Tablo 2. Literatür karşılaştırması

\begin{tabular}{lccccc}
\hline & $\boldsymbol{\varepsilon}^{\prime}$ & $\boldsymbol{\varepsilon}^{\prime \prime}$ & Frekans (GHz) & Nem & Referans \\
\hline Kauçuk yaprağı & $22-18$ & $8-6$ & $3,3-4,9$ & $\% 46$ & {$[4]$} \\
Mısır yaprağı & $34-28$ & $8-5$ & $3,3-4,9$ & $\% 60$ & {$[7]$} \\
Misır yaprağı & $20-18$ & $5,5-4$ & $3,3-4,9$ & $\% 63$ & {$[28]$} \\
Yonca yaprağı & $38-33$ & $19-13$ & $3,3-4,9$ & $\% 73$ & {$[29]$} \\
Elma yaprağı & $31-14$ & $30-15$ & $3,3-4,9$ & $\% 21,4$ & Bu çalışma \\
\hline
\end{tabular}

\section{Sonuç ve Öneriler}

Bu çalışmada, sabit sıcaklıkta NO ve frekansa bağlı olmak üzere birbiriyle aynı aileden olan elma (Malus communis) ve armut (Pyrus communis) yapraklarının dielektrik karakteristikleri ölçüm sonuçlarıyla elde edilmiştir. Elma yapraklarının dielektrik ölçüm verileri kullanarak eğri uydurma yöntemiyle yeni bir model önerilmiştir. Bu model elma türüne akraba olan armut yaprağıyla ilgili dielektrik ölçümleriyle modelin doğruluğu test edilmiştir. Ölçümlerde Dalga Kılavuzu İletim Hattı tekniği kullanılmıştır. Ölçümler WR229 dalga kılavuzuyla 3.30-4.90 GHz frekans bandında yapılmıştır. Bütün frekans bandında elma için $\varepsilon^{\prime}$ değerleri 6-50, $\varepsilon^{\prime \prime}$ değerleri ise 10-36 aralığında değiştiği tespit edilmiştir. $\mathrm{Bu}$ model, elma türüyle aynı aileden olan armut yaprağının dielektrik ölçüm sonuçlarıyla karşılaştırılarak önerilen modelin doğruluğu test edilmiştir. Modelin performansını göstermek için determinasyon katsayısı $R^{2}$ ve Hataların Ortalama Kare Kökü (RMSE) değerleri sirasıyla 0,995 ve 0,625 olarak elde edilmiştir.

\section{Teşekkür}

Bu çalışmada ölçümlerin gerçekleştirildiği Akdeniz Üniversitesi Endüstriyel ve Medikal Uygulamalar Mikrodalga Araştırma Merkezi (EMUAM)'a teşekkür ederim (Destek Numarası: 2007K120530-DPT).

\section{Yazarların Katkısı}

Çalışmanın tasarlanmasında, ölçümlerin ve hesaplamaların yapılması ve yorumlanması $\% 100$ yazarın kendisine aittir. 


\section{Çıkar Çatışması Beyanı}

Yazarlar arasında herhangi bir çıkar çatışması bulunmamaktadır.

\section{Araştırma ve Yayın Etiği Beyanı}

Yapılan çalışmada araştırma ve yayın etiğine uyulmuştur.

\section{Kaynaklar}

[1] Faktorová D., Isteníková K. 2011. Modelling of Scattering Parameters in Biological Tissues. Skin, 1 (41): 1-7.

[2] Nelson S.O. 2006. Agricultural Applications of Dielectric Measurements. IEEE Transactions on Dielectrics and Electrical Insulation, 13 (4): 688-702.

[3] Nelson S. 1999. Dielectric Properties Measurement Techniques and Applications. Transactions of the ASAE-American Society of Agricultural Engineers, 42 (2): 523-530.

[4] Chuah H., Kam S., Chye Y. 1997. Microwave Dielectric Properties of Rubber and Oil Palm Leaf Samples: Measurement and Modelling. International Journal of Remote Sensing, 18 (12): 26232639.

[5] Kocakusak A., Colak B., Helhel S. 2016. Frequency Dependent Complex Dielectric Permittivity of Rubber and Magnolia Leaves and Leaf Water Content Relation. Journal of Microwave Power and Electromagnetic Energy, 50 (4): 294-307.

[6] Romanov A.N., Ulanov P.N. 2018. Seasonal Differences in Dielectric Properties of Dwarf Woody Tundra Vegetation in a Microwave Range. IEEE Transactions on Geoscience and Remote Sensing, 57 (6): 3119-3125.

[7] Ulaby F.T., El-Rayes M.A. 1987. Microwave Dielectric Spectrum of Vegetation-Part II: DualDispersion Model. IEEE Transactions on Geoscience and Remote Sensing, 5: 550-557.

[8] Afzal A., Mousavi S.F. 2008. Estimation of Moisture in Maize Leaf by Measuring Leaf Dielectric Constant. International Journal of Agriculture \& Biology, 10: 66-68.

[9] Colak B. 2019. Moisture Content Effect of Banana Leaves to Radio Frequency Absorbing Microwave and Optical Technology Letters.

[10] Kaur R., Aul G.D., Chawla V. 2015. Improved Reflection Loss Performance of Dried Banana Leaves Pyramidal Microwave Absorbers by Coal for Application in Anechoic Chambers. Progress In Electromagnetics Research, 43: 157-164.

[11] Jayamani E., Hamdan S., Ezhumalai P., Bakri M.K. 2016. Investigation on Dielectric and Sound Absorption Properties of Banana Fibers Reinforced Epoxy Composites. Jurnal Teknologi, 78: 610.

[12] Khaled D., Novas N., Gazquez J.A., Garcia R.M., Agugliaro F.M. 2015. Fruit and Vegetable Quality Assessment via Dielectric Sensing. Sensors, 15 (7): 15363-15397.

[13] Navarrete A., Mato R.B., Dimitrakis G., Lester E., Robinson J.R.,Cocero M.J., Kingman S. 2011. Measurement and Estimation of Aromatic Plant Dielectric Properties, Application to Low Moisture Rosemary. Industrial Crops and Products, 33 (3): 697-703.

[14] Kamaruddin M.J., Yusof M.S.B.M., Ngadi N., Zakaria Z.Y., Arsad A., Kidam K. 2017. Dielectric Properties for Extraction of Orthosiphon Stamineus (Java Tea) Leaves. Chemical Engineering Transactions, 56: 1771-1776.

[15] Kraszewski A.W., Nelson S.O. 2004. Microwave Permittivity Determination in Agricultural Products. Journal of Microwave Power and Electromagnetic Energy, 39 (1): 41-52.

[16] Venkatesh M., Raghavan G. 2005. An Overview of Dielectric Properties Measuring Techniques. Canadian Biosystems Engineering, 47 (7): 15-30.

[17] Nelson S.O. 2010. Fundamentals of Dielectric Properties Measurements and Agricultural Applications. Journal of Microwave Power and Electromagnetic Energy, 44 (2): 98-113.

[18] Van Emmerik T., Steele-Dunne S., Judge J., van de Giesen N. 2015. A comparison Between Leaf Dielectric Properties of Stressed and Unstressed Tomato Plants. IEEE International Geoscience and Remote Sensing Symposium (IGARSS). 
[19] Itolikar A.B., Kurtadikar M.L. 2017. Microwave Measurements of Dielectric Properties of Corn Vegetation at C-Band and Comparison with Debye-Cole Dual Dispersion Model. Journal of Microwaves, Optoelectronics and Electromagnetic Applications, 16 (4): 954-965.

[20] Krraoui H., Mejri F., Aguili T. 2016. Dielectric Constant Measurement of Materials by a Microwave Technique: Application to the Characterization of Vegetation Leaves. Journal of Electromagnetic Waves and Applications, 30 (12): 1643-1660.

[21] Van Emmerik T.H. 2013. Diurnal Differences in Vegetation Dielectric Constant as a Measure of Water Stress. Yüksek Lisans Tezi, Delft University of Technology, Civil Engineering, Delft, Hollanda.

[22] Durmuş M., Salman A.O., Yıldırım T.Ş. 2018. NRW Metodu İle Malzemelerin Elektromanyetik Parametrelerinin Bulunmasi. Kocaeli Üniversitesi Fen Bilimleri Dergisi, 1 (1): 13-19.

[23] Yaw K.C. 2012. Measurement of Dielectric Material Properties: Application Note, Rhode \& Schwarz.

[24] Anonim. 2004. De-Embedding and Embedding S-Parameter Networks Using a Vector Network Analyzer, Uygulama Notu.

[25] Helhel S., Kurnaz O. 2016. Buried Metal Detection within the Wooden Block by X-Band Measurements. Microwave and Optical Technology Letters, 58 (5): 1245-1253.

[26] Ye L., Li C., Sun X., Jin S., Chen B., Ye X., Fan J. 2016. Thru-Reflect-Line Calibration Technique: Error Analysis for Characteristic Impedance Variations in the Line Standards. IEEE Transactions on Electromagnetic Compatibility, 59 (3): 779-788.

[27] Chung B.K. 2007. Dielectric Constant Measurement for Thin Material at Microwave Frequencies. Progress In Electromagnetics Research, 75: 239-252.

[28] Li Z., Zeng J., Chen Q., Bi H. 2014. The measurement and model construction of complex permittivity of vegetation. Science China Earth Sciences, 57 (4): 729-740.

[29] Shrestha B.L., Wood H.C., Sokhansanj S. 2011. Microwave dielectric properties of alfalfa leaves from 0.3 to $18 \mathrm{GHz}$. IEEE Transactions on Instrumentation and Measurement, 60: 2926-2933. 